\title{
REGENERAÇÃO DO FÍGADO DE RATOS APÓS OCLUSÃO PARCIAL DA DRENAGEM VENOSA HEPÁTICA
}

\section{Hepatic regeneration after parcial oclusion of hepatic vein drainage in rats}

\author{
Luiz Roberto Farion de AGUIAR, Paulo Afonso Nunes NASSIF, \\ Carmen Australia Paredes Marcondes RIBAS, Marcelo Mazza do NASCIMENTO, Julio Cesar WIEDERKER, \\ Jan Pawel Andrade PACHNICKI, Edmar STIEVEN-FILHO
}

ABCDDV/648

Aguiar LRF, Nassif PAN, Ribas CAPM, Nascimento MM, Wiederker JC, Pachnicki JPA, Stieven-Filho E. Regeneração do fígado de ratos após oclusão parcial da drenagem venosa hepática. ABCD Arq Bras Cir Dig 2009;22(2):89-95

RESUMO - Introdução - A regeneração hepática é um mecanismo para superar a perda de tecido funcional do fígado. Este processo é estudado através de diferentes métodos. Objetivo - Avaliar o efeito da oclusão parcial da drenagem venosa hepática sobre a regeneração do fígado remanescente de ratos submetidos à hepatectomia parcial. Método - Foram colhidas biópsias de fígado em 30 ratos Wistar machos, e a seguir realizada hepatectomia a dois terços. Os animais foram divididos em três grupos: um grupo controle e dois grupos de estudo, submetidos a diferentes graus de estenose da veia hepática direita. Após 96 horas do estímulo para regeneração hepática, todos submeteram-se à outra biópsia hepática. Analisaram-se os fragmentos por imunoistoquímica para os marcadores Ki-67 e fator de von Willebrand. Para a leitura das amostras utilizou-se o sistema SAMBA 4000. A deposição de colágeno foi avaliada pela coloração tricrômico de Masson. Resultados - A proliferação celular dos animais submetidos à hepatectomia parcial e estenose moderada ou severa da veia hepática direita persistiu mais elevada quando comparada ao grupo controle. O Índice de Marcação para o Ki-67 foi significativamente mais elevado após a hepatectomia nos grupos submetidos à oclusão parcial da veia hepática, tanto moderada quanto severa. A expressão de fator de von Willebrand estava diminuída após a hepatectomia parcial nos três grupos. Houve pouco depósito de colágeno no tecido hepático nos animais dos dois grupos com estenose da veia hepática direita. Conclusão - A oclusão parcial da drenagem venosa hepática em ratos submetidos à hepatectomia parcial prolonga o tempo de proliferação de células hepáticas quando comparado aos animais com veias de calibre normal. Como consequência, também houve atraso na restauração da matriz extracelular e na formação de novos vasos sinusoidais. DESCRITORES - Regeneração hepática. Oclusão vascular. Imunoistoquímica. Ratos.

\section{INTRODUÇÃO}

A regeneração hepática é um mecanismo de superação orgânica contra a perda de tecido hepático funcional frente a qualquer tipo de lesão, seja ela química, viral, traumática acidental ou cirúrgica ${ }^{12}$.

$\mathrm{Na}$ mitologia grega, ela é contada através do mito de Prometeu, apresentado por Ésquilo no século V AC, que revelou o segredo do fogo dos deuses do Olimpo e foi condenado a alimentar diariamente uma águia com parte de seu fígado. Entretanto, durante a noite ocorria a regeneração e assim era fonte renovável de alimento ao pássaro e prolongado sofrimento ao mitológico personagem ${ }^{16}$.

Com a finalidade de documentar de forma concisa a presença e extensão da atividade regenerativa hepática, criaram-se modelos experimentais. Atualmente, o melhor para estímulo da regeneração do fígado é a hepatectomia parcial - remoção cirúrgica dos lobos mediano e lateral esquerdo do fígado de ratos, preservando cerca de $30 \%$ do órgão ${ }^{10}$. Neste modelo, a recuperação da massa hepática

Trabalho realizado no Programa de Pós-Graduação em Princípios da Cirurgia da Faculdade Evangélica do Paraná/Hospital Universitário Evangélico de Curitiba, Curitiba, PR, Brasil

Endereço para correspondência: Luiz Roberto Farion de Aguiar, e-mail: ipem@evangelico.org.br ressecada ocorre no período de duas a três semanas.

A regeneração estimulada pela hepatectomia é processo de proliferação de todas as linhas celulares maduras que compõem o órgão íntegro, como os hepatócitos, células biliares epiteliais, células endoteliais, células de Kupffer e células estreladas ${ }^{15}$.

O processo de regeneração hepática, depois de desencadeado, pode ser avaliado por diversos métodos, tais como o peso do fígado, o número de mitoses, os componentes do $\mathrm{ADN}$, o índice de síntese de antígenos nucleares avaliados por imunoistoquímica, a expressão de genes, as variações dos níveis de proteínas séricas, testes sorológicos, determinações enzimáticas de marcadores de proliferação e citometria ${ }^{4}$.

Doenças como insuficiência cardíaca direita, doenças venoclusivas, síndrome de Budd-Chiari ${ }^{11}$, bem como em hepatectomias extensas, transplante hepático onde utilizase doador vivo ou pequenos enxertos ou mesmo o uso da técnica de piggyback ${ }^{18}$, podem alterar a drenagem venosa hepática, provocando quadro de hipertensão portal.

O efeito do baixo débito hepático provoca dilatação e congestão na microcirculação, alterando o aporte de nutrientes e fatores hepatotróficos. O problema é mais intenso na zona 3 , frequentemente acompanhado de atrofia dos hepatócitos ${ }^{13}$. Lesões nos sinusóides podem evoluir para 
fibrose e insuficiência hepática, tendo como consequência a perda do órgão ou enxerto implantado.

A compreensão destes mecanismos, a instituição de tratamentos e técnicas cirúrgicas visando restabelecer a drenagem sanguínea hepática normal, evitariam as consequências funestas desta situação clínica. Uma maneira viável de monitorar e acompanhar este processo seria através de método imunoistoquímico.

Os objetivos desta pesquisa são: a) estudar, após 96 horas do estímulo regenerativo, o efeito da oclusão parcial da veia hepática direita sobre a regeneração do figado após hepatectomia a 70\%; b) analisar, nas mesmas condições, a regeneração hepática com ou sem oclusão parcial da veia hepática direita; c) avaliar a presença de fibras colágenas no tecido hepático.

\section{MÉTODO}

Este trabalho foi realizado no Programa de Pós-Graduação em Princípios da Cirurgia da Faculdade Evangélica do Paraná/Hospital Universitário Evangélico de Curitiba, Curitiba, PR, Brasil, tendo sido aprovado pelo Comitê de Ética em Pesquisa da Sociedade Evangélica Beneficente de Curitiba.

Foram utilizados 30 ratos adultos jovens, machos, da linhagem Wistar, com peso variando entre 240 e $351 \mathrm{~g}$, tendo acesso livre à água e dieta específica para a espécie em ambiente com controle de temperatura e ciclos alternados de 12 horas de luminosidade e obscuridade. Foram divididos em três grupos de 10, de forma aleatória.

Os animais do grupo controle (CTL) foram submetidos à laparotomia, biópsia no lobo direito do fígado, hepatectomia dos lobos mediano e lateral esquerdo. No grupo estenose moderada (MOD), os animais submeteram-se à biópsia hepática, hepatectomia dos lobos hepáticos mediano e lateral esquerdo e plicatura da veia hepática direita com molde de $1,1 \mathrm{~mm}$ de diâmetro. Os do grupo estenose severa (SEV) tiveram o lobo direito biopsiado, os lobos mediano e lateral esquerdo do fígado ressecados e realizada plicatura da veia hepática direita com molde de 1,7 mm de diâmetro.

Decorridas 96 horas da intervenção cirúrgica, biópsias dos fígados remanescentes foram obtidas. Em seguida, todos os animais foram mortos com dose letal inalatória de éter e imediatamente submetidos à hepatectomia total do fígado remanescente.

\section{Técnica operatória - primeira operação}

Os ratos foram anestesiados 30 minutos antes do início da operação, com injeção intramuscular de cetamina e clorpromazina e obteve-se bom nível anestésico, sem comprometimento respiratório. Foram aplicados, via intramuscular, $0,3 \mathrm{~mL}$ por $100 \mathrm{~g}$ de peso corporal de solução composta por $10 \mathrm{~mL}$ de cetamina na concentração de $50 \mathrm{mg} / \mathrm{mL}$ e $1,5 \mathrm{~mL}$ de clorpromazina na concentração de $5 \mathrm{~g} / \mathrm{mL}$, o que manteve nível anestésico por aproximadamente três horas.

Os animais foram pesados e tricotomizados. Posicionados em decúbito dorsal com contenção das quatro patas. Utilizou-se solução de polivinil- pirrolidona-iodo para a antissepsia. Após colocação de campos cirúrgicos, realizou- se laparotomia mediana.

Nos animais do grupo CTL foram obtidas biópsias nos lobos direitos dos fígados e a seguir realizou-se a dissecação dos lobos mediano e lateral esquerdo, ligadura de seus pedículos vasculares com fio de algodão 4-0, e ressecção dos mesmos, o que caracteriza hepatectomia de 70\%10 (Figura 1). A síntese da parede abdominal foi realizada em dois planos de sutura contínua com fio poliglecaprone 25, 4-0.

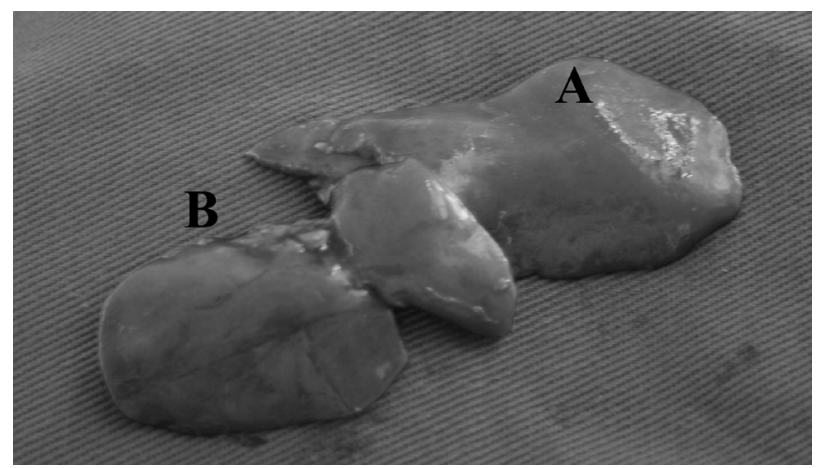

FIGURA 1 - Hepatectomia parcial no rato: em A lobo lateral esquerdo; em B lobo mediano

Nos ratos do grupo MOD, após as biópsias e hepatectomias realizadas de forma similar ao grupo CTL, efetuou-se a dissecação e reparo das veias hepáticas direitas. Posicionou-se um molde de $1,1 \mathrm{~mm}$ de diâmetro sobre as veias e confeccionou-se plicaturas com fio de polipropileno 7-0, o que promoveu moderada estenose (Figura 2).

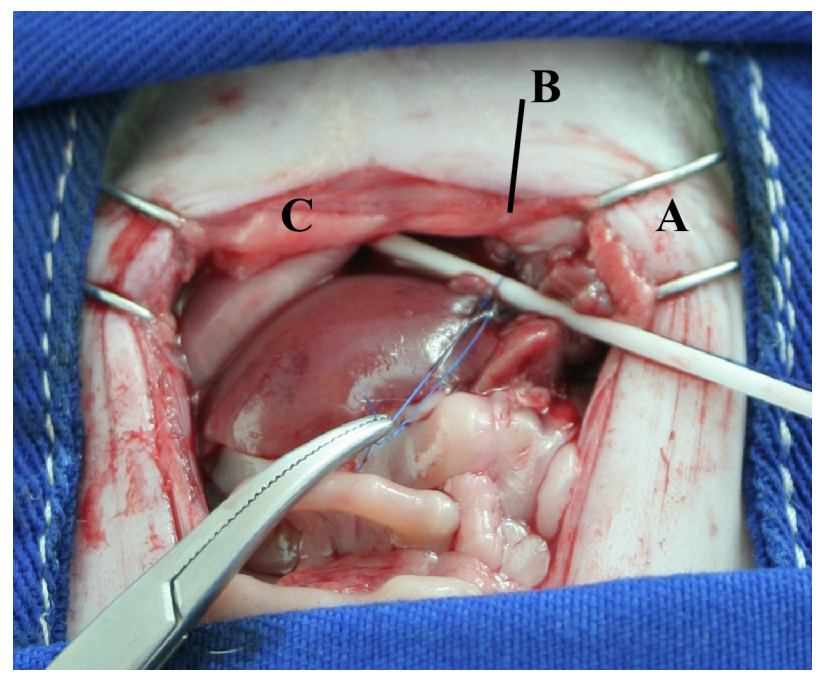

FIGURA 2 - Plicatura da veia hepática direita com molde de 1,1 $\mathrm{mm}$ de diâmetro. Nota-se em A cateter com 1,1 mm de diâmetro; em B plicatura da veia hepática direita; em $\mathrm{C}$ fígado remanescente - lobo direito.

Nos animais do grupo SEV, procedeu-se de maneira semelhante ao grupo MOD, sendo diferente apenas o diâmetro do molde, que neste grupo foi de $1,7 \mathrm{~mm}$, o que ocasionou severa estenose (Figura 3). 


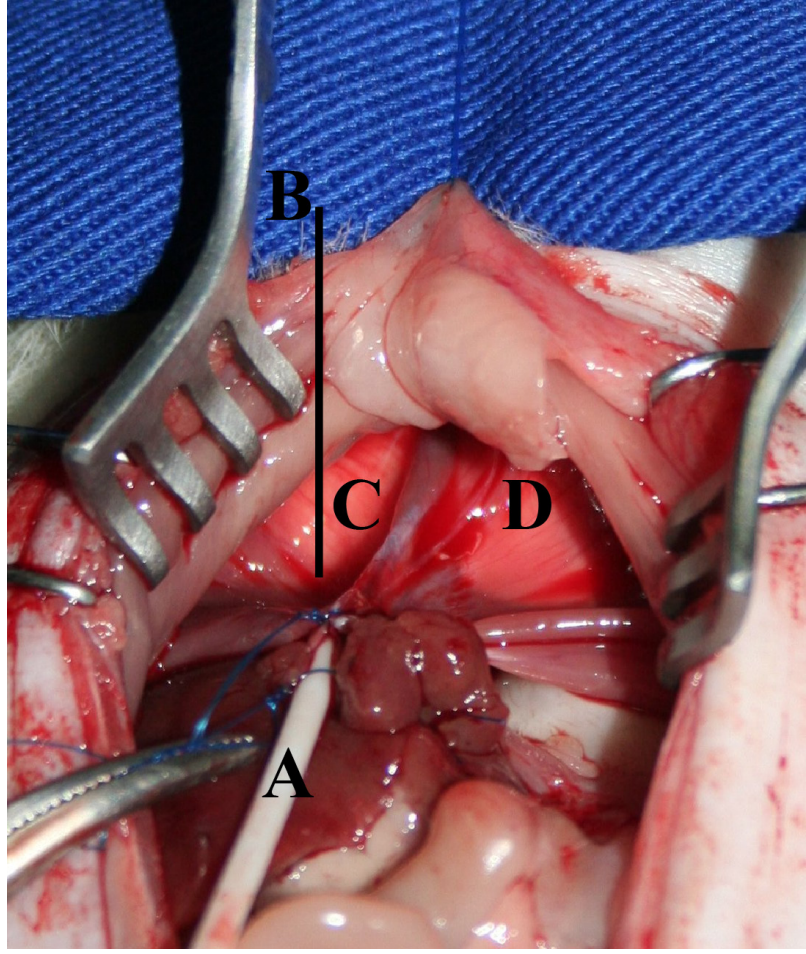

FIGURA 3 - Plicatura da veia hepática direita com molde de1,7 mm de diâmetro. Nota-se em A cateter com 1,7 $\mathrm{mm}$ de diâmetro; em $\mathrm{B}$ plicatura da veia hepática direita; em $\mathrm{C}$ fígado remanescente - lobo direito; em $\mathrm{D}$ músculo diafragma esquerdo

Todos os produtos das biópsias hepáticas, que apresentavam-se em fragmentos de cerca $1 \mathrm{~cm} 3$, foram acondicionados em formol tamponado e encaminhados para estudo anatomopatológico.

\section{Técnica operatória - segunda operação}

Após 96 horas da primeira intervenção, todos os ratos submeteram-se a outro procedimento anestésico da mesma maneira do que na primeira, e submetidos à nova laparotomia seccionando-se os fios das suturas anteriores. Obtiveram-se biópsias dos lobos direitos dos fígados remanescentes em fragmentos com cerca de $1 \mathrm{~cm} 3$, os quais foram acondicionados em formol tamponado e encaminhados para estudo anatomopatológico.

A seguir, todos foram mortos com inalação letal de éter e imediatamente submetidos à hepatectomia total do fígado remanescente.

Os fígados obtidos dos ratos do grupo CTL foram pesados, e o calibre de suas veias hepáticas direitas medido. Os dos animais dos grupos MOD e SEV foram pesados, e o calibre de suas veias hepáticas direitas medido (Figura 4).

A seguir, a plicatura foi desfeita e o diâmetro das veias hepáticas direitas medido novamente. Para pesagem das amostras utilizou-se balança de precisão modelo V-1200 da marca Acculab, e a medida dos vasos sanguíneos aferida com paquímetro eletrônico digital série 727 da marca Starrett.

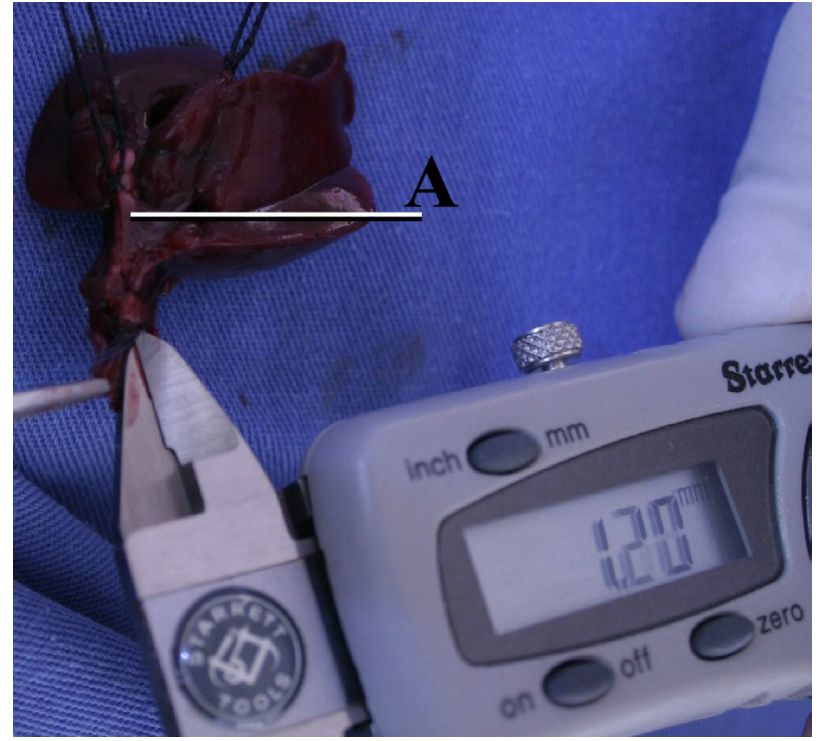

FIGURA 4 - Medida do calibre da veia hepática com plicatura.

\section{Tratamento das amostras}

As biópsias hepáticas coletadas nos dois episódios cirúrgicos forneceram fragmentos de aproximadamente 1 $\mathrm{cm} 3$, os quais foram mergulhados em formol tamponado. Então, este material foi encaminhado ao laboratório para processamento, inclusão, corte dos blocos histológicos para imunoistoquímica e tricrômico de Masson. Em seguida, com o material preparado realizou-se a leitura das lâminas no Sistema SAMBA 4000.

A leitura seguiu o padrão: núcleos em negro; citoplasmas, fibrina e fibrilas nervosas em vermelho; colágeno e muco ácido em azul ou verde. Teve por objetivo distinguir fibras colágenas de fibras nervosas, destacar fibromatoses incipientes ou estabelecidas. Na avaliação imunoistoquímica os marcadores Ki-67 e fator VIII são corados em marrom.

Na leitura do sistema SAMBA 4000 foram avaliados dois parâmetros:1) índice de marcação (IM) que representa o número de células em proliferação; 2) densidade óptica (DO), que é a quantidade de ADN no núcleo.

\section{Método estatístico}

Os resultados obtidos foram avaliados, utilizando-se o software SPSS 13 for Windows, em relação ao peso corporal (g), peso do fígado (g), diâmetro em milímetros $(\mathrm{mm})$ da veia hepática direita antes da plicatura (VHPRE) e diâmetro em milímetros (mm) da veia hepática direita após plicatura (VHPOS).

Para avaliação dos diversos parâmetros, foram utilizados os seguintes testes estatíticos: KolmogorovSmirnov, ANOVA, posterior post-hoc de Tukey, T pareado, Jonckheere-Terpstra, com significância estatística para $P<0,05$. 


\section{RESULTADOS}

\section{Animais de experimentação}

Um animal, do grupo controle, morreu 90 horas após a hepatectomia parcial. Por ocasião da segunda operação, os animais do grupo CTL apresentavam seus fígados de coloração vinho clara, brilhante, sem sinais de necrose, sangrando quando biopsiados. No grupo MOD, os ratos apresentavam o tecido hepático com cor vinho escura, que sangrava após a realização da biópsia, e apresentavam pequenas áreas de necrose no figado remanescente. Os do grupo SEV possuíam fígado de aspecto congesto, cor vinho escura e heterogênea, com extensas áreas de necrose, porém vascularizados no local de biópsia.

Com relação ao peso corporal, peso do fígado e ao diâmetro da veia hepática direita, não houve diferença estatisticamente significativa nos três grupos estudados (Tabela 1).

TABELA 1 - Teste de normalidade

\begin{tabular}{ccccc}
\hline & $\begin{array}{c}\text { PESO } \\
\text { CORPORAL(g) }\end{array}$ & $\begin{array}{c}\text { PESO DO } \\
\text { FÍGADO(g) }\end{array}$ & $\begin{array}{c}\text { VHPRE } \\
(\mathbf{m m})\end{array}$ & $\begin{array}{c}\text { VHPOS } \\
(\mathbf{m m})\end{array}$ \\
\hline $\mathbf{n}$ & 29 & 29 & 29 & 29 \\
$\mathbf{M}$ é - & 297,52 & 10,45 & 4,32 & 1,45 \\
$\mathbf{d i a}$ & 29,17 & 1,53 & 0,58 & 1,07 \\
$\mathbf{D p}$ & 1,00 & 0,96 & 0,96 & 0,11 \\
$\mathbf{P}$ & & & & \\
\hline
\end{tabular}

Na avaliação dos diâmetros das veias hepáticas direitas após plicatura nos grupos MOD e SEV e o grupo CTL houve diferença com significância estatística entre os grupos (Figura 1).

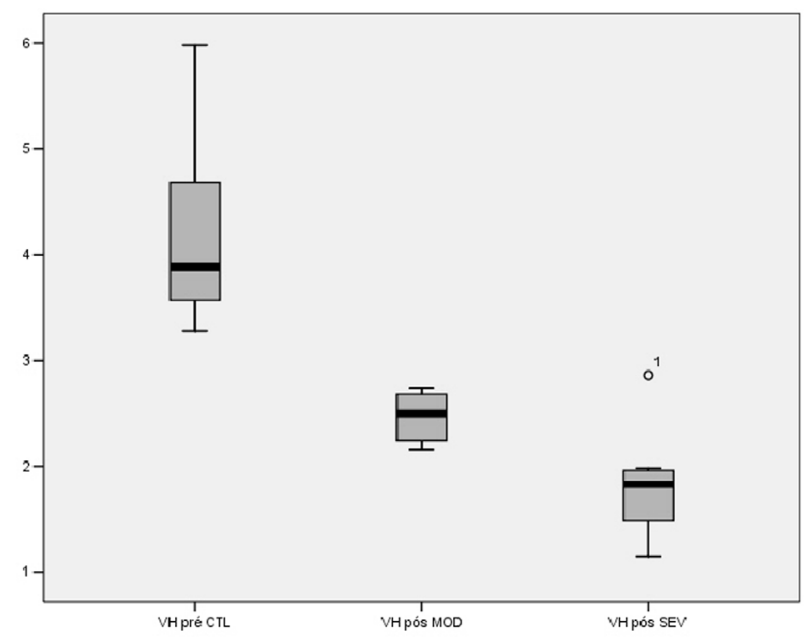

FIGURA 5- Diâmetro das veias hepáticas direitas do grupo CTL e diâmetro das veias hepáticas após plicatura nos grupos MOD e SEV

\section{Índice de marcação e densidade óptica do marcador Ki-67}

Os valores descritivos para a análise do marcador Ki-67 dos três grupos referentes ao IM e a DO antes da hepatectomia parcial (pre-marcação e pre-dens) e 96 horas após (pós-marcação e pós-dens), são apresentados na Tabela 2.
TABELA 2 - Análise descritiva para os valores de índice de marcação e densidade óptica do marcador Ki-67

\begin{tabular}{llllll}
\hline Variáveis & n & mínimo & máximo & média & Dp \\
\hline Pré-marcação CTL (\%) & 9 & 27,6 & 66,99 & 47,24 & 12,97 \\
Pós-marcação CTL (\%) & 9 & 25,76 & 78,77 & 47,20 & 17,89 \\
Pré-dens CTL & 9 & 49,49 & 79,11 & 62,94 & 10,44 \\
Pós-dens CTL & 9 & 38,24 & 52,58 & 45,52 & 4,69 \\
Pré-marcação MOD (\%) & 10 & 24,36 & 61,71 & 40,57 & 13,90 \\
Pós-marcação MOD (\%) & 10 & 51,47 & 93 & 66,74 & 13,88 \\
Pré-dens MOD & 10 & 62,06 & 82,28 & 73,46 & 6,93 \\
Pós-dens MOD & 10 & 40,89 & 69,33 & 52,78 & 9,68 \\
Pré-marcação SEV (\%) & 9 & 21,73 & 63,48 & 35,55 & 14,93 \\
Pós- marcação SEV (\%) & 9 & 48,87 & 89,65 & 70,78 & 12,27 \\
Pré-desn SEV & 9 & 58,8 & 83,3 & 70,65 & 9,25 \\
Pós-dens SEV & 9 & 50,67 & 62,91 & 58,54 & 4,17 \\
\hline
\end{tabular}

Aplicando-se o teste T pareado para índice de marcação na expressão de Ki-67, no grupo CTL não houve diferença significativa, mas nos grupos MOD e SEV houve; quando aplicado este mesmo teste para densidade óptica, houve diferença estatisticamente significativa em todos os grupos (Tabela 3).

TABELA 3 - Teste T pareado para os índices de marcação e densidades ópticas do marcador Ki-67

\begin{tabular}{ll}
\hline Pares de variáveis & $\boldsymbol{P}$ \\
\hline Pré-marcação CTL - pós-marcação CTL & $0,996^{*}$ \\
Pré-marcação MOD - pós-marcação MOD & $0,003^{* *}$ \\
Pré-marcação SEV - pós- arcação SEV & $0,003^{* *}$ \\
Pré-dens CTL- pós-dens CTL & $0,003^{* *}$ \\
Pré-dens MOD - pós-dens MOD & $0,001^{* *}$ \\
Pré-desn SEV - pós-dens SEV & $0,006^{* *}$ \\
\hline
\end{tabular}

* $P<0,05$ ** $P<0,01$

\section{Índice de marcação e densidade óptica do marcador} fator de von Willebrand

Os valores descritivos para a análise do marcador FVIII dos três grupos, referentes ao índice de marcação e a densidade óptica antes da hepatectomia parcial (pré-marcação e pré-dens) e 96 horas após (pós-marcação e pós-dens), são apresentados na Tabela 4.

TABELA 4 - Análise descritiva dos valores de índice de marcação e densidade óptica do marcador FVIII

\begin{tabular}{llllll}
\hline Variáveis & n & Mínimo & Máximo & Média & Dp \\
\hline Pré-marcação CTL (\%) & 9 & 31,07 & 88,16 & 68,65 & 16,86 \\
Pós-marcação CTL (\%) & 9 & 17,50 & 59,16 & 38,24 & 16,71 \\
Pós-dens CTL & 9 & 30,93 & 70,41 & 50,08 & 15,38 \\
Pré-dens CTL & 9 & 29,34 & 44,24 & 33,94 & 4,67 \\
Pré-marcação MOD (\%) & 10 & 52,95 & 87,19 & 74,26 & 12,06 \\
Pós-marcação MOD (\%) & 10 & 29,22 & 93,19 & 49,88 & 19,61 \\
Pré-dens MOD & 10 & 37,82 & 68,13 & 54,64 & 9,76 \\
Pós-dens MOD & 10 & 39,30 & 53,42 & 45,60 & 4,48 \\
Pré-marcação SEV (\%) & 10 & 51,77 & 86,47 & 74,09 & 10,74 \\
Pós-marcação SEV (\%) & 10 & 21,87 & 73,82 & 43,88 & 14,23 \\
Pré-dens SEV & 10 & 38,88 & 68,60 & 51,99 & 8,98 \\
Pós-dens SEV & 10 & 34,86 & 46,10 & 40,02 & 3,84 \\
\hline
\end{tabular}


Aplicando-se o teste T pareado para índice de marcação e densidade óptica na expressão de FVIII, houve diferença com significância estatística nos três grupos avaliados (Tabela 5).

TABELA 5 - Teste T pareado para índice de marcação e densidade óptica para o marcador FVIII

\begin{tabular}{ll}
\hline Pares de variáveis & $\boldsymbol{P}$ \\
\hline Pré-marcação CTL - pós-marcação CTL & $0,005^{* *}$ \\
Pré-marcação MOD - pós-marcação MOD & $0,005^{* *}$ \\
Pré-marcação SEV - pós-marcação SEV & $0,000^{* *}$ \\
Pré-dens CTL - pós-dens CTL & $0,009^{* *}$ \\
Pré-dens MOD - pós-dens MOD & $0,041^{*}$ \\
Pré-dens SEV - pós-dens SEV & $0,005^{* *}$ \\
\hline
\end{tabular}

* $P<0,05 * * P<0,01$

\section{Deposição de colágeno}

Verificou-se discreta deposição de fibras colágenas no fígado, coradas em azul, após 96 dias do estímulo regenerativo (Figura 6).

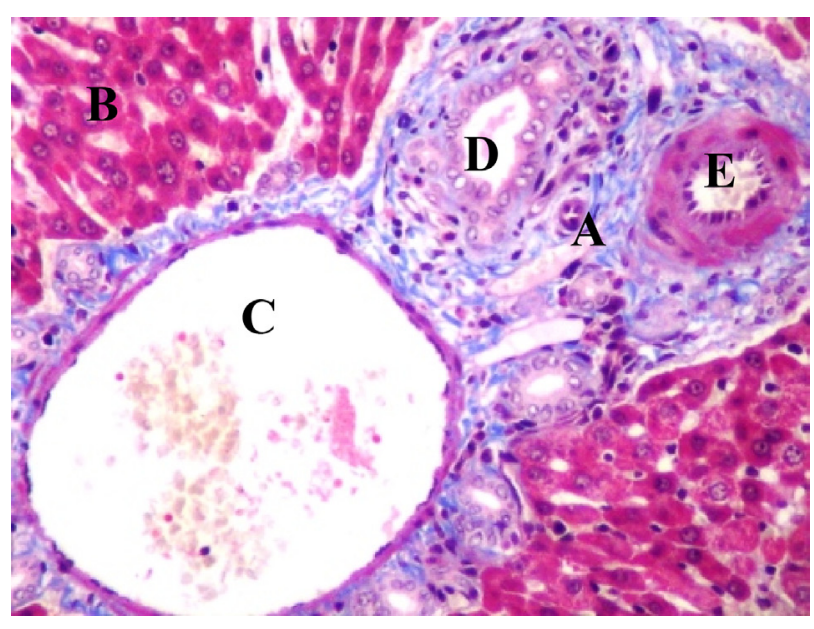

FIGURA 6 - Coloração pelo tricrômico de Masson: A) colágeno; (B) hepatócitos; (C) veia porta; (D) ducto biliar; (E) artéria hepática. (aumento 100X)

Os dados descritivos referentes à presença de colágeno e sua distribuição nos grupos são apresentados na Tabela 6 .

TABELA 6 - Distribuição da deposição de colágeno nos grupos CTL, MOD e SEV

\begin{tabular}{|c|c|c|c|c|c|c|}
\hline & & & \multicolumn{3}{|c|}{ Grupos } & \multirow{2}{*}{ Total } \\
\hline & & & CTL & MOD & SEV & \\
\hline \multirow{8}{*}{ Deposição de colágeno } & \multirow{2}{*}{$\mathbf{0}$} & $\mathbf{n}$ & 0 & 0 & 3 & 3 \\
\hline & & $\%$ do Total & 0,00 & 0,00 & 10,34 & 10,34 \\
\hline & \multirow{2}{*}{1} & n & 5 & 8 & 6 & 19 \\
\hline & & $\%$ do Total & 17,24 & 27,59 & 20,69 & 65,52 \\
\hline & \multirow{2}{*}{2} & n & 3 & 2 & 1 & 6 \\
\hline & & $\%$ do Total & 10,34 & 6,90 & 3,45 & 20,69 \\
\hline & \multirow{2}{*}{3} & n & 1 & 0 & 0 & 1 \\
\hline & & $\%$ do Total & 3,45 & 0,00 & 0,00 & 3,45 \\
\hline \multirow{2}{*}{\multicolumn{2}{|c|}{ Total }} & $\mathrm{n}$ & 9 & 10 & 10 & 29 \\
\hline & & $\%$ do Total & 31,03 & 34,48 & 34,48 & 100,00 \\
\hline
\end{tabular}

Na avaliação da deposição de colágeno, observou-se associação entre a presença de colágeno e o grau de estenose, sendo estatisticamente significante. Houve relação inversamente proporcional, isto é, nos animais com estenose venosa mais severa a deposição de colágeno era mais discreta.

\section{DISCUSSÃO}

O processo de regeneração hepática pode ser induzido experimentalmente por qualquer intervenção que promova remoção ou morte celular do tecido hepático. A perda de unidades funcionais do fígado estimula a proliferação celular visando a restauração da massa original ou necessária para a homeostase.

O volume hepático, no rato, é restaurado em torno de 10 dias e o aspecto é uma versão aumentada das porções não ressecadas. De forma consensual, é aceito que a regeneração hepática humana é similar a de roedores, porém com diferenças temporais nas respostas ao estímulo inicial, a hepatectomia parcial ${ }^{14}$. No ser humano ainda não foram estabelecidos os tempos necessários a cada etapa, contudo evidências sugerem que haja rápida regeneração nas primeiras duas semanas, e a seguir gradual aumento de tamanho até cessar em torno de seis a 12 meses, quando o fígado tenha restaurado aproximadamente $75 \%$ de sua massa original. Em estudo feito com 17 pacientes submetidos a vários tipos de hepatectomia, foi demonstrado, através de tomografia axial computadorizada, que quanto maior o volume ressecado maior a capacidade de regeneração; e hepatectomias extensas induzem a aumento do fluxo sanguíneo e distensão vascular no fígado remanescente, o que talvez contribua para a regeneração ${ }^{8}$.

Em estudos recentes, procura-se qual é o evento que desencadeia o início da resposta regenerativa. Após a hepatectomia parcial, em menos de 30 minutos, o fator nuclear B (NFB) é ativado e migra para o núcleo celular onde estimula genes envolvidos com a replicação celular'. Durante a proliferação de hepatócitos ocorre a liberação de fatores de crescimento que estimulam a divisão celular de outras células hepáticas. Também essenciais para a proliferação celular, proto-oncogenes são expressos de forma específica, sequencial e regulada: c-jun é essencial para a diferenciação dos hepatócitos; c-fos é necessário na fase posterior da proliferação, enquanto o c-ras surge na fase de síntese de ADN e mitose, e o p53 visa prevenir a proliferação celular desordenada ${ }^{12}$.

Utilizam-se métodos imunoistoquímicos na avaliação da regeneração hepática, principalmente após o desenvolvimento de anticorpos capazes de reconhecer antígenos que não se degradam durante o processamento histológico ${ }^{3}$. A imunoistoquímica é técnica essencialmente qualitativa, mas aplicações quantitativas podem ser realizadas para determinar a quantidade de antígeno presente na amostra a ser analisada ${ }^{2}$.

Basoglu, et al. ${ }^{6}$, estudaram a regeneração com a K-67 e constataram a eficácia do método em ratos. Brown, et al. ${ }^{7}$ avaliaram que a utilização do Ki-67 como ferramenta de pesquisa é limitada entre espécies diferentes mas, com 
a produção de outros anticorpos que identificam epítopos da proteína Ki-67, como o anticorpo MIB-1, estendeuse a utilização para outros mamíferos. Para animais de laboratório, houve avanços com o desenvolvimento dos anticorpos MIB-5 e TEC-3.

Neste experimento, a avaliação pelo marcador Ki-67 mostrou que, 96 horas após a hepatectomia nos animais do grupo CTL, o número de células proliferando foi semelhante ao encontrado previamente ao estímulo regenerativo. Os animais submetidos à estenose de suas veias hepáticas direitas, após quatro dias da hepatectomia parcial, apresentaram número de células proliferando maior que aquele encontrado antes da hepatectomia, porém com menor intensidade.

Tarlá, et al. ${ }^{17}$, destacam que após três dias o aspecto histológico é diferente do tecido hepático normal, ocorrendo a proliferação dos hepatócitos em aglomerados não vascularizados e ainda sem síntese de nova MEC. A seguir, diminui a proliferação e ocorre a migração de células para os aglomerados, iniciando a angiogênese, com pequeno número de células endoteliais.

Já Abshagen, et al. ${ }^{1}$, encontraram mais hipertrofia que hiperplasia em animais submetidos à hepatectomia parcial até o oitavo dia após a operação. Observaram menor densidade de vasos sinusoidais, porém os existentes encontravam-se dilatados. Também havia menor densidade de células estreladas. Notaram que quando os hepatócitos param a síntese de $\mathrm{ADN}$, aumenta a transcrição de colágeno no interstício. Relataram ainda que no início da regeneração hepática, a matriz extracelular não é sintetizada em consequência da proliferação dos hepatócitos, e está reduzida.

$\mathrm{O}$ fígado produz metaloprotease que degrada o fator VIII, e que está diminuída logo após a hepatectomia e também em órgãos fibróticos ou cirróticos. Portanto, os níveis do fator de von Willebrand, no plasma, tornam-se bastante elevados e vão lentamente diminuindo nas primeiras 24 horas após a hepatectomia. Nos casos de fibrose hepática os níveis continuam altos. Como um marcador de células endoteliais, é localizado na túnica interna dos vasos, principalmente nas grandes veias, células do endotélio sinusoidal expressam o fator VIII quando ocorre a capilarização, início do processo de fibrose hepática. Mas, quando ocorre injúria ao fígado, ele será depositado nos novos vasos formados. Sendo uma molécula de adesão pode interagir com componentes da MEC, tais como integrinas, colágeno, fibronectina e plaquetas.

Baruch, et al. ${ }^{5}$, encontraram valores aumentados de fator de von Willebrand para os animais hepatectomizados até o quinto dia do pós-operatório, usando técnica semelhante à utilizada neste estudo. Os relatos existentes sobre a expressão do fator VIII pelas CES do fígado são conflitantes havendo casos positivos e negativos relatados.

Os resultados encontrados neste trabalho, depois de 96 horas do estímulo regenerativo, mostraram que a expressão de fator VIII estava significativamente diminuída em relação aos valores obtidos antes da hepatectomia em todos os grupos estudados e que houve deposição de colágeno discreta em todos os animais.

\section{CONCLUSÃO}

A oclusão parcial da drenagem venosa hepática em ratos submetidos à hepatectomia parcial prolonga o tempo de proliferação de células hepáticas quando comparado aos animais com veias de calibre normal. Como consequência, também houve atraso na restauração da matriz extracelular e na formação de novos vasos sinusoidais.

Aguiar LRF, Nassif PAN, Ribas CAPM, Nascimento MM, Wiederker JC, Pachnicki JPA, Stieven-Filho E. Hepatic regeneration after parcial oclusion of hepatic vein drainage in rats. ABCD Arq Bras Cir Dig 2009;22(2):89-95

ABSTRACT - Background - Hepatic regeneration is a mechanism to overcome the loss of liver functional tissue. This process has been studied through different methods. Aim - To evaluate the effect of the partial occlusion of the hepatic venous drainage on the regeneration of the remainder livers in rats submitted to partial hepatectomy. Method - Liver biopsies from 30 male Wistar rats were collected, and after they were submitted two-third hepatectomy. The animals were divided in three groups: a control group and two study groups, which were submitted to different degrees of the right hepatic vein stenosis. After 96 hours of the stimulation for regeneration all rats were submitted to another hepatic biopsy. The analysis of the fragments was performed by immunohistochemistry for the Ki-67 and von Willebrand factor markers. The reading of the samples was done using the SAMBA 4000 system. Collagen deposition was evaluated by the trichromic Masson's staining. Result - The cellular proliferation of the animals submitted to partial hepatectomy and stenosis of the right hepatic vein persists higher when compared to control group. The Label Index for Ki-67 was significantly higher post-hepatectomy in groups submitted to hepatic vein partial occlusion. The expression of von Willebrand factor was strongly decreased after the hepatectomy in all groups. There was little deposit of collagen in the hepatic tissue of animals with hepatic vein stenosis. Conclusion - Partial occlusion of the hepatic venous drainage in rats submitted to partial hepatectomy prolongs the time of hepatic cells proliferation when compared to the animals with vein of normal caliber. Consequently, there will be also a delay in the restoration of the extracellular matrix and in the formation of new sinusoidal vessels.

HEADINGS - Hepatic regeneration. Vascular occlusion. Immunohistochemistry. Rats. 


\section{REFERÊNCIAS}

1. Abshagen K, Eipel C, Menger MD, Vollmar B. Comprehensive analysis of the regenerating mouse liver: an in vivo fluorescence microscopic and immunohistological study. J Surg Res. 2006 Aug;134(2):354-62.

2. Alves MTS, Roman LCM. Estudo do efeito de distintos períodos de fixação em formalina e métodos de recuperação antigênica na técnica de imuno-histoquímica. Jornal Brasileiro de Patologia e Medicina Laboratorial 2005;41(1):43-9.

3. Arias V, Mazza PL, Funke MAA. Processamento tecidual para análise imunoistoquímica de receptores hormonais em carcinoma mamário: dois momentos em um laboratório de anatomia patológica; correlação dos resultados com método bioquímico. Jornal Brasileiro de Patologia e Medicina Laboratorial 2003;39(3):223-8

4. Assy N, Minuk GY. Liver regeneration: methods for monitoring and their applications. J Hepatol. 1997 Apr;26(4):945-52.

5. Baruch Y, Neubauer K, Shenkar L, Sabo E, Ritzel A, Wilfling T, Ramadori G. Von Willebrand factor in plasma and in liver tissue after partial hepatectomy in the rat. J Hepatol. 2002 Oct;37(4):471-7

6. Basoglu M. Balik AA, Kavak I, Gündogdu C, Erman Z, Yildirgan I, Ören D. Effects of Growth Hormone on Hepatic Regeneration. Turk J Med Sci. 2000;30:529-34

7. Brown DC, Gatter KC. Ki67 protein: the immaculate deception? Histopathology. 2002 Jan;40(1):2-11.

8. Chen MF, Hwang TL, Hung CF. Human liver regeneration after major hepatectomy. A study of liver volume by computed tomography. Ann Surg. 1991 Mar;213(3):227-9.

9. Fausto N. Liver regeneration. J Hepatol. 2000;32(1 Suppl):19-31.
10. Higgins GM, Anderson RM. Experimental pathology of the liver: Restoration of the liver of the white rat following partial surgical removal. Arch Pathol. 1931;12:186-202.

11. Janssen HL, Garcia-Pagan JC, Elias E, Mentha G, Hadengue A, Valla DC. BuddChiari syndrome: a review by an expert panel. J Hepatol. 2003 Mar;38(3):36471.

12. Jesus RP, Waitzberg DL, Campos FG. Regeneração hepática: papel dos fatores de crescimento e nutrientes. Rev Ass Méd Brasil 2000;46(3):242-54.

13. Kakar S, Kamath PS, Burgart LJ. Sinusoidal dilatation and congestion in liver biopsy: is it always due to venous outflow impairment? Arch Pathol Lab Med. 2004 Aug;128(8):901-4.

14. Mangnall D, Bird NC, Majeed AW. The molecular physiology of liver regeneration following partial hepatectomy. Liver Int. $2003 \mathrm{Apr}$;23(2):124-38.

15. Ramalho FS, Ramalho LNZ, Zucoloto S, Silva Jr OC. Regeneração Hepática -Algumas definições num universo de incertezas. Acta Cir Bras. 1993;8(4):17789.

16. Ribeiro Jr WA. Atlas, Prometeu e a serpente. Portal Graecia Antiqua, 2000. Disponível em: < http://greciantiga.org//img/vfn/i095.asp > Acesso em: 14.12.2007.

17. Tarlá MR, Ramalho F, Ramalho LNZ, Silva TCE, Brandão DF, Ferreira J, Silva OCE, Zucoloto S. A molecular view of liver regeneration. Acta Cir Bras. 2006-A;21:58-62.

18. Wang SL, Sze DY, Busque S, Razavi MK, Kee ST, Frisoli JK, Dake MD. Treatment of hepatic venous outflow obstruction after piggyback liver transplantation. Radiology. 2005 Jul;236(1):352-9.

Fonte de financiamento: não há Conflito de interesse: não há Recebido para publicação: 02/02/2009 Aceito para publicação: 21/04/2009 